\title{
Development of Russian Driverless Electric Vehicle
}

\author{
Andrey Mikhailovich Saykin, Sergey Evgenievich Buznikov, Denis Vladimirovich Endachev, \\ Kirill Evgenievich Karpukhin, Alexey Stanislavovich Terenchenko \\ Central Scientific Research Automobile and Automotive Institute "NAMI", ul. Avtomotornaya 2, \\ Moscow, 125438, Russia
}

\begin{tabular}{|c|c|}
\hline Article Info & ABSTRACT \\
\hline & \multirow{6}{*}{$\begin{array}{l}\text { This article overviews the history of development of driverless vehicles both } \\
\text { in Russia and the World. Foreign experience of development of driverless } \\
\text { vehicles, including electric traction, is analyzed. Main stages of creation of } \\
\text { experimental NAMI driverless electric vehicle are revised. Main engineering } \\
\text { solutions are described concerning development of advanced NAMI } \\
\text { driverless electric vehicle, its major components and control systems. } \\
\text { Projects aimed at environmental safety of passengers in NAMI driverless } \\
\text { electric vehicle are exemplified. Results of bench scale and running tests of } \\
\text { NAMI driverless electric vehicle are summarized. Major advantages of } \\
\text { driverless energy efficient and environmentally clean transport are } \\
\text { demonstrated. }\end{array}$} \\
\hline Jun 1, 2017 & \\
\hline Revised Mar 20, 2018 & \\
\hline Accepted May 27, 2018 & \\
\hline Keyword: & \\
\hline $\begin{array}{l}\text { Air purification system } \\
\text { Control system } \\
\text { Driverless vehicle }\end{array}$ & \\
\hline
\end{tabular}

Driverless vehicle

Electric vehicle

Energy efficiency

Energy storage system

Navigation system

Vehicle

Vision system

Copyright (C) 2018 Institute of Advanced Engineering and Science. All rights reserved.

\section{Corresponding Author:}

Andrey Mikhailovich Saykin,

Central Scientific Research Automobile and Automotive Institute "NAMI"

ul. Avtomotornaya 2, Moscow, 125438, Russia.

Email: saykin.a.m@mail.ru

\section{INTRODUCTION}

Recently on the roads of various countries of the World driverless vehicles begin to appear, they are controlled by complicated automatic pilot systems. The most known participant in this market is Google Inc. company. Not only this company attempts to eliminate the necessity of a human at the wheel. All major car manufacturers in Japan, Germany, US, Italy, China, and France actively develop driverless (autonomous) vehicles and relevant technologies. Numerous undisclosed projects are developed under orders from defense industry, hence, the results of such works are unavailable in public sources. Complex knowledge intensive engineering solutions, software, sensors of control systems are considered as double-purpose products [1-3]. According to forecasts of analytical agencies wide scale application of driverless (autonomous) vehicles is expected unless and until 2025.

\section{RESEARCH METHODS}

This study was based on system analysis, including decomposition and optimization of engineering solutions. In addition, path planning, motion of vehicle in space (environment) were used. Artificial intelligence, theory of sets and mathematical logic were applied. 


\section{MAIN PART}

Active development of driverless vehicles by leading foreign car manufacturers started in early 1980-s for passenger cars, freight cars, agricultural machines and military purpose vehicles, interfactory vehicles, transport traffic in modern logistic centers and storage sites. Numerous leading car manufacturers, such as General Motors, Ford, Mercedes Benz, Volkswagen, Audi, BMW, Volvo, are involved in development of driverless vehicles as well as large manufacturers of components for these driverless vehicles, such as Continental, Bosch, Delphi.

Activities on development of driverless vehicles are also performed in Russian Federation. Leading $\mathrm{R}^{\wedge} \mathrm{D}$ institutes, universities and car manufacturers, such as NAMI, Moscow Automobile and Road Construction State Technical University (MADI), Moscow polytechnic university, PAO KamAZ and others.

In the years 2014-2016 State research center NAMI in Russian Federation developed, manufactured and tested experimental electric driverless vehicle (Figure 1).
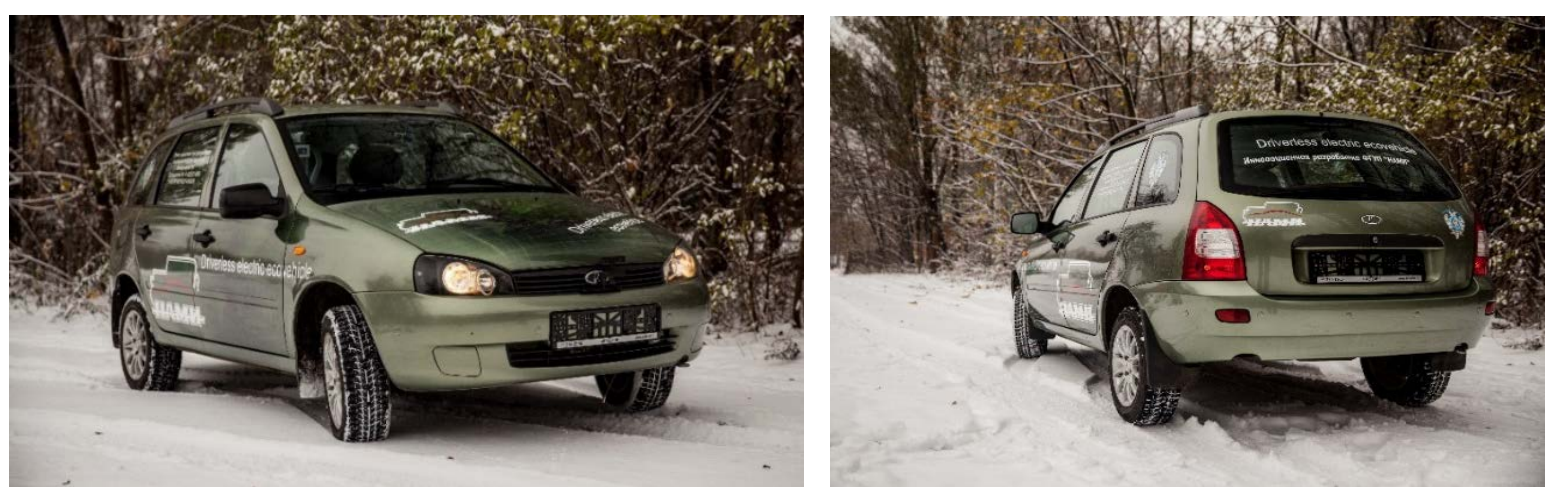

Figure 1. NAMI driverless electric vehicle (external view)

Table 1. Main Specifications of NAMI Driverless Electric Vehicle

\begin{tabular}{lc}
\hline \multicolumn{1}{c}{ Vehicle model } & LADA-Kalina 1117 \\
Traction module & 30 \\
Nominal power $(\mathrm{kW})$ & 70 \\
Maximum power $(\mathrm{kW})$ & 30 \\
Recovery power $(\mathrm{kW})$ & \\
Automotive battery of traction module & 13 \\
Power intensity $(\mathrm{kW} * \mathrm{~h})$ & 316 \\
Nominal voltage $(\mathrm{V})$ & 250 \\
Maximum discharge current $(\mathrm{A})$ & 100 \\
Maximum charge current $(\mathrm{A})$ & \\
Steering system & with electromechanical amplifier \\
Type & \\
Braking system & Disc-type \\
Front brakes & Drum-type \\
Rear brakes & \\
Suspension & Samper strut \\
Front suspension type & Trailing arm \\
Rear suspension type & \\
Car body & $4040 \mathrm{~mm}$ \\
Length & $1700 \mathrm{~mm}$ \\
Width & $1500 \mathrm{~mm}$ \\
Height & $1430 \mathrm{~mm}$ \\
Front track, mm & $1410 \mathrm{~mm}$ \\
Rear track, mm & $160 \mathrm{~mm}$ \\
Clearance & 1200 \\
Curb weight & \\
Operating specifications & $20 \mathrm{~s}$ \\
Acceleration time to $100 \mathrm{~km} / \mathrm{h}$ & $120 \mathrm{~km} / \mathrm{h}$ \\
Maximum speed & 6 \\
Complete charge time $(\mathrm{h})$ & 1.5 \\
Accelerated charge time $(\mathrm{h})$ & $-30 \ldots+50$ \\
Operating temperature $\left({ }^{\circ} \mathrm{C}\right)$ & \\
&
\end{tabular}


Actuating mechanisms of the NAMI driverless electric vehicle are as follows: linear actuators; servo drive unit; steering electric amplifier.

Instruments of the driverless electric vehicle are as follows: sensor of linear motions of actuators; linear potentiometer.

The following components are used in the machine vision system of motion control of driverless electric vehicle: AXIS PI346 video camera; SLR 1 lidar; ultrasound sensors.

Driverless electric vehicle operates in three control modes:

1. "Driver" mode

In this mode the driverless electric vehicle is used as common electric vehicle without any restrictions.

2. "Remote control" mode

In this mode driverless electric vehicle can be controlled by PC with specialized software or by dedicated joystick.

3. "Autonomous motion" mode

This mode is driverless control of electric vehicle by means of machine vision system and actuators. Driverless vehicle can either move along corridor passing by obstacles; or reproduce preset trajectory; or perform parallel parking.

Propulsion unit in the NAMI driverless electric vehicle is a Solectria Azure Dynamics $70 \mathrm{~kW}$ threephase asynchronous engine with air cooling equipped with a DMOC 445 invertor. The torque from traction electric motor to vehicle drive wheels is transferred by means of reducer with differential. In order to avoid overloads capable to break the reducer the reducer input shaft is connected with the shaft of traction electric motor by overload coupling. The reducer shell is rigidly connected with the shell of traction electric motor. The traction electric motor with the reducer in vehicle motor compartment is mounted using three-point mounting system of power unit.

Electricity accumulation system is comprised of eight modules, each contains twelve AMP20M1HD-A batteries - 96 battery cells in total. Nominal voltage: $316.8 \mathrm{~V}$, internal impedance: $57.6 \mu \Omega$. Control system of battery cell is located in the top part. It is comprised of four boards, each board controls 12 cells. The control system is intended for management and balancing of battery cells, for checking of integrity of battery circuits, voltage and temperature of cells, and for data transfer to battery management system (BMS). Special software provides connection, adjustment, and diagnostics of battery management system from PC via COM port (USART1) or CAN.

Environmental safety of passengers in the NAMI driverless electric vehicle is provided by two air cleaning systems in passenger compartment. They are located in luggage compartment (Figure 2). Clean air from the systems is supplied via ducts located inside the passenger compartment near front seats. In addition, gas analyzer for monitoring of impurity content in the air is placed in the compartment. Controller of air cleaning system is connected to the gas analyzer and the system itself. The latter operates in recirculation mode, that is, it intakes air from the passenger compartment, cleans the air and supplies the cleaned air to the passenger compartment. The gas analyzer transfers the data on air composition to the controller which constantly analyzes content of harmful substance in the passenger compartment and controls operation modes of air cleaning system [4-6].

External view of the NAMI driverless electric vehicle with installed battery cells of traction modules installed in luggage compartment and air cleaning and distribution systems is illustrated in Figure 2.

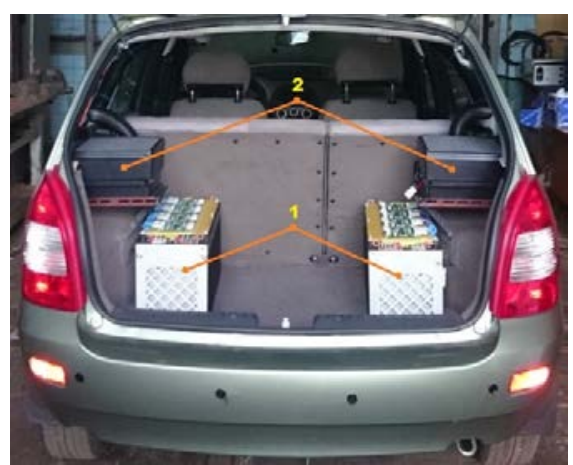

Figure 2. NAMI driverless electric vehicle with automotive batteries of traction module installed in luggage compartment (1) and air cleaning and distribution system in passenger compartment (2)

Autonomous motion of driverless electric vehicle is provided by motion control system including machine vision system, navigation and orientation system, information management system, and actuators. 
The machine vision system generates the image of surroundings, provides recognition of other vehicles, road obstructions, road signs, traffic lights, road marking [7-10]. The information management system is the core of motion management system of NAMI driverless electric vehicle, which is responsible for route arrangement, urgent decisions depending on surrounding traffic, and generation of control signals to actuators. In accordance with the control signals the actuators directly act upon units and systems of NAMI driverless electric vehicle, substituting driver actions. The navigation and orientation system determines the current position of NAMI driverless electric vehicle. The actuator system is comprised of control actuators of electric transmission, clutching, gear shifting, steering, brakes, starter, light and sound equipment, and others.

The motion management system of NAMI driverless electric vehicle is comprised of sensors, drives, electronic control unit with components and control board. The machine vision system is comprised of AXIS PI346 video cameras, SLR 100 lidar, ARS 300 radar, eight ultrasound sensors (parktronics), SS series, LTP linear potentiometer and two SANV-10 electromechanic actuators. Two AXIS PI346 cameras are installed behind the front windscreen in upper corners, and one camera behind rear windshield in its center (Fig. 4), which provides maximum visibility in front of and behind the vehicle. Application of AXIS PI346 video cameras in the machine vision system of NAMI driverless electric vehicle provides accurate recognition of road signs and marks [11-13].

Figure 3 illustrates the video cameras and lidars installed in front part of the compartment of NAMI driverless electric vehicle. Figure 4 illustrates the video camera installed in rear part of the compartment of NAMI driverless electric vehicle. Figure 5 illustrates the radar installed in the front part of NAMI driverless electric vehicle.

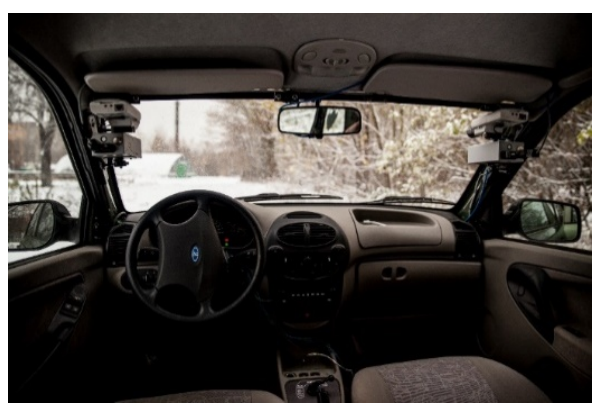

Figure 3. Location of video cameras in passenger compartment behind windscreen of driverless electric vehicle

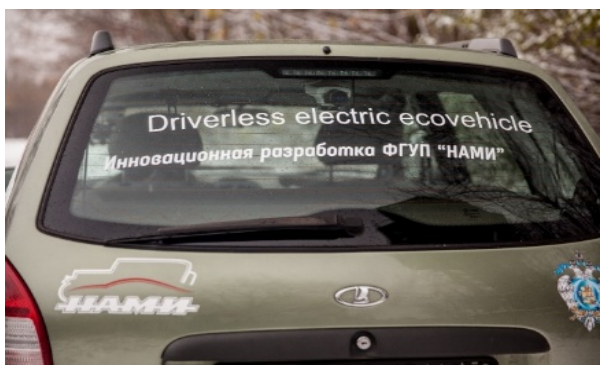

Figure 4. Location of video cameras in passenger compartment behind rear windshield of nami driverless electric vehicle

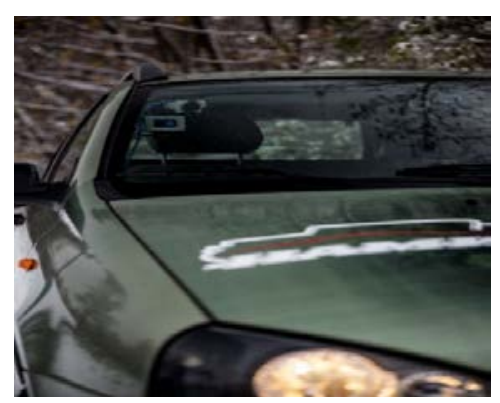

Figure 4. Illustrates the video camera installed in rear part of the compartment of nami driverless electric vehicle

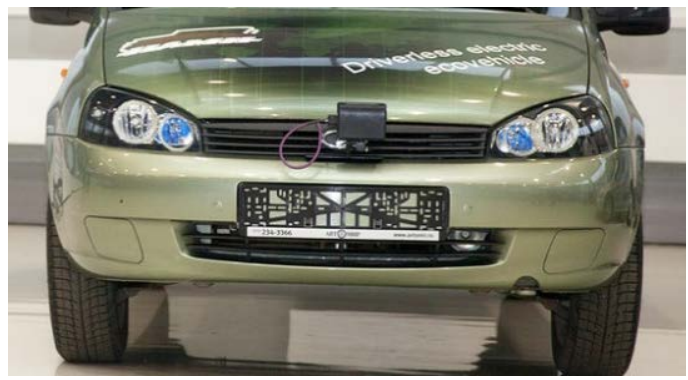

Figure 5. ARS 300 radar installed on radiator grille of nami driverless electric vehicle

A PS-A-4006 ultrasound sensor facilitates detection of objects and obstructions in short-range zone, automatic parking and provides sensor feedback for accurate vehicle steering in narrow road corridors. The steering system includes LTP linear potentiometer. The LTP linear potentiometer installed on steering rack in engine room facilitates high accurate detection of wheel positions at any instant. 
The major component of the system is the central processing unit which is a multiprocessor perforimng the following main functions:

1. Connection with external wireless devices (BLUETOOTH, GPS, and other);

2. Acquiring image of surrounding near NAMI driverless electric vehicle (radars, lidars, video cameras, parktronics) and its subsequent processing;

3. Acquiring information about short range surrounding from ultrasound sensors and its subsequent processing;

4. Data processing from all sensors of the system;

5. Calculation of motion parameters of NAMI driverless electric vehicle in real time in accordance with the preset algorithms;

6. Generation of control commands to external actuators in accordance with current state and motion algorithm.

Integration of the control system into vehicle is provided by another device: Mechanism control unit. Its main functions are as follows:

1. Processing of position sensors of control mechanisms of NAMI driverless electric vehicle;

2. Control actions for actuators of NAMI driverless electric vehicle;

3. Data transfer concerning state of control mechanisms of NAMI driverless electric vehicle;

4. Obtaining of control commands from central processing unit.

Mechanism control unit provides integration with the following mechanisms and units of NAMI driverless electric vehicle:

1. Actuators of accelerator pedal, primary and parking braking systems, clutch;

2. Steering drive;

3. Traction invertor;

4. $\quad$ Lighting control (position lamps, low and high beams);

5. Wiper and washer control;

6. Window raiser control.

Data exchange between the devices is performed by CAN bus, it provides high transfer reliability as well as interference protection in electrical system. The system is powered by battery cells of NAMI driverless electric vehicle.

Electromechanic drive in the braking system controls application of brake pedal and hand parking brake. SANV-10 actuator enables fast application of primary brake and parking brake, hence, fast vehicle stoppage. Two SANV-10 actuators are used in the braking system. One of them is installed in engine room and the other in tunnel assembly.

Motion control system performs general computations of vehicle motion: position coordinates, recognition of objects around the vehicle, detection of obstructions. Central processing unit is connected to the system of orientation and navigation in order to process and obtain global coordinates of vehicle position, it communicates with external devices via Bluetooth and is equipped with data storage unit. Image recognition unit is connected to cameras which inspect surrounding objects. High rate of image recognition is supported by parallel computations. Obstructions are detected by means of radar control unit and two lidar units. All units are connected to common CAN bus, which enables controlling actions and data acquisition. The software of motion control system of experimental NAMI driverless electric vehicle executes main functions of motion control, including maintaining of safe speed, safe distance to vehicle ahead, motion path with regard to preset one, control of turn indicators, audio and light stop alarms, as well as solution of navigation task reserved by satellite system. The software is based on Inka-NAMI proprietary algorithmic and programmed approaches aimed at preventing of vehicle collision with constrictions.

Receiver of the navigation system is installed in passenger compartment. The antenna output connector is in accordance with SMA standard. The antenna is installed in the roof center. Efficient operation of antennas is supported by the important condition: shadowing of GLONASS/GPS satellites by at least $140^{\circ}$. Antenna is fed by high frequency coaxial cable. Powering of the navigation module from $12 \mathrm{~V}$ vehicle network is provided by a source of secondary supply (DC-DC converter) on the basis of DA1 TES 2N-2410 diode microcircuit with protection against reverse polarity and conductive noises. The navigation system can be powered from a battery. The interconnection between the receiver and network equipment is provided by ADM 1485 and 74VHC 04 microcircuits. A user of navigation data can directly connect to full-scale NV08C-CSM-BRD navigation receiver. All components of control system of NAMI driverless electric vehicle, except for navigation antenna, are installed in passenger compartment and protected against external impacts and mechanical damages. 

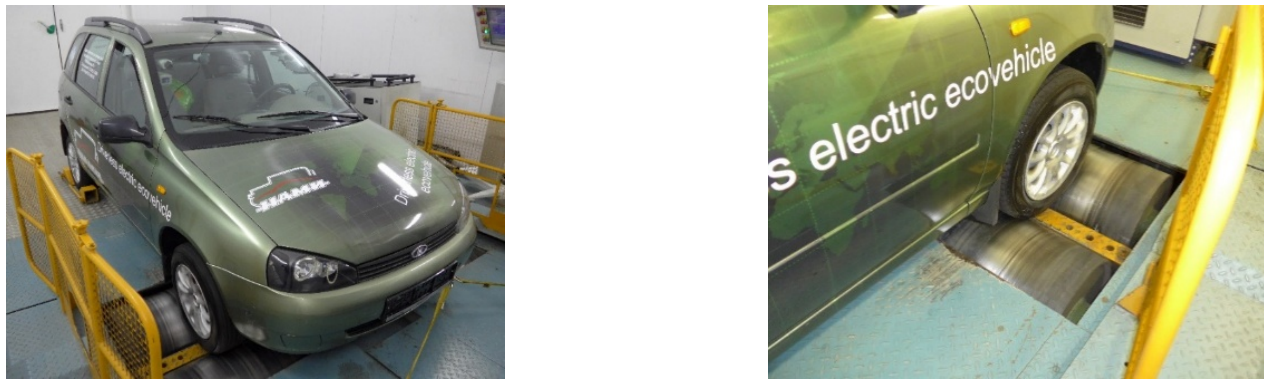

Figure 6. Bench Scale NAMI Driverless Electric Vehicle
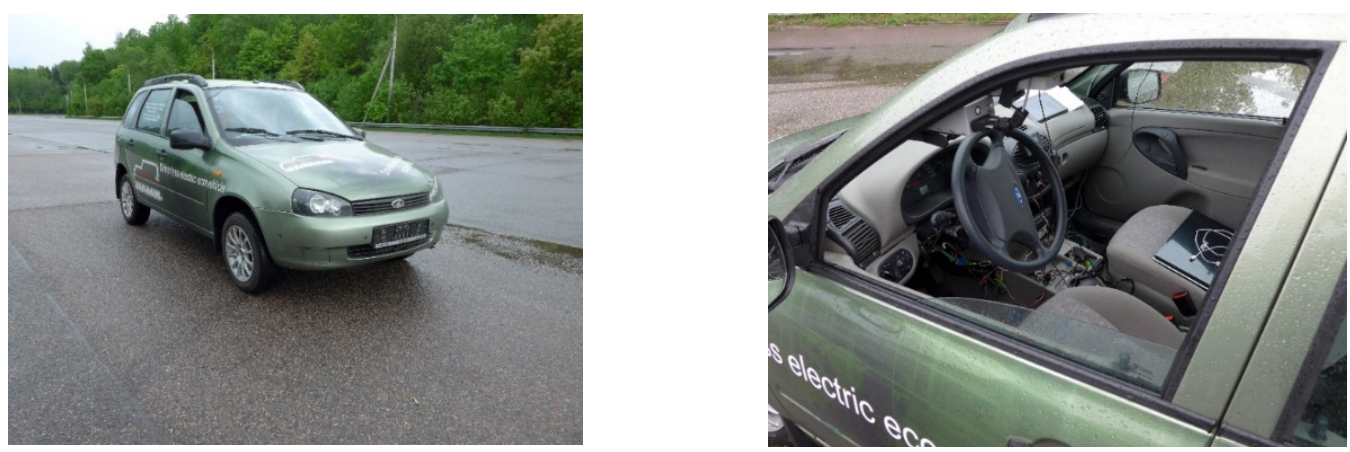

Fig. 7. Driving Tests of NAMI Driverless Electric Vehicle

The following performances were achieved after tests of NAMI driverless electric vehicle: onecharge driving distance - at least $50 \mathrm{~km}$, maximum driving speed - at least $120 \mathrm{~km} / \mathrm{h}$, acceleration time to 100 $\mathrm{km} / \mathrm{h}$ - at least $20 \mathrm{~s}$, and the motion control system maintains maximum driving speed of $30 \mathrm{~km} / \mathrm{h}$; recognition of obstructions - road users; recognition of road signs - at least 30 ones; detection of road marks main, on straight ways; detection of vehicle position - with the accuracy to $5 \mathrm{~m}$; maintaining of preset distance to vehicles ahead - to $3 \mathrm{~m}$; maintaining of driving speed - with the accuracy to $3 \mathrm{~km} / \mathrm{h}$; audio and light alarms - with response rate up to $0.5 \mathrm{~s}$. The air cleaning system eliminates harmful inclusions in the passenger compartment of electric vehicle to the maximum permitted level established by Hygienic regulations GN 2.1.6.1338.

\section{RESULTS AND DISCUSSION}

The obtained experimental results are aimed at development of R\&D and engineering complex of Russian Federation in the fields of safety, energy efficiency, and energy saving in transport industry, at development projects aimed at improvement of traffic safety and environmental safety of passengers, at implementation into educational process of technical higher schools, at implementation into business activities of automobile companies [14-17].

Implementation of the experimental results would enable achievement of cardinally new level of energy efficiency, environmental and traffic safety of single vehicles and overall traffic system, including:

1. Improvement of traffic safety due to decrease in traffic accidents by means of application of driverless vehicle control and air cleaning in passenger compartments;

2. Improvement of environmental performances of vehicles in comparison with existing ones due to application of electric traction and driverless control;

3. Reduction of harmful impact of vehicles on environment due to elimination of harmful pollutions of electric vehicle;

4. Improvement of environmental safety of passengers by means of efficient air cleaning in passenger compartment;

5. Improvement in disposal and recirculation rate of vehicles in comparison with the existing ones. 


\section{CONCLUSIONS}

The achieved performances of NAMI driverless electric vehicle in total and its constituents (traction module, motion control system, electricity accumulation system) are close to those of global analogs and is superior to those of Russian analogs. The achieved performances of air cleaning and distribution system in passenger compartment exceed those of all known global and Russian analogs concerning environmental safety of passengers. The developed NAMI driverless electric vehicle is implemented in this configuration for the first time in global practice.

\section{ACKNOWLEDGMENTS}

This work was supported by the agreement \# 14.625.21.0006 with the Ministry of Education and Science of Russian Federation (unique project identifier RFMEFI62514X0006) to create an experimental model of a driverless environmentally friendly electric vehicle.

\section{REFERENCES}

[1] M. Yguel, C. Tay, M. Keat, C. Braillon, C. Laugier and O. Ayvehicled, "Dense Mapping for telemetric sensors: efficient algorithms and sparse representation,” In Proceedings of Robotics: Science and Systems Conference, 2007.

[2] B. Mihailov, “Technical vision in control systems of mobile objects,” In R.R. Nazirova (ed.), Proceedings of the Scientific Conference-Workshop. Iss. 4, Moscow, Publishing house of Lomonosov Moscow state university, pp: 191-202, 2011.

[3] ISO 15765-4:2011 (E), Road vehicles - Diagnostic communication over Controller Area Network (Do CAN). Part 4: Requirements for emissions-related systems. Second edition, 2011.

[4] A. Saykin, S. Bakhmutov, A. Terenchenko, D. Endachev, K. Karpukhin and V. Zarubkin, "Tendency of creation of “driverless” vehicles abroad,” Bioscience Biotechnology Research Asia, vol. 11, pp. 241-246, 2014.

[5] A. Terenchenko, K. Karpukhin and R. Kurmaev, "Features of operation of electromobile transport in the conditions of Russia,” Paper of EVS 28 International Electric Vehicle Symposium and Exibition, KINTEX, Korea, 2015.

[6] A. Saykin, S. Buznikov and K. Karpukhin, "The analysis of technical vision problems typical for driverless vehicles,” Research journal of pharmaceutical, biological and chemical sciences, vol. 7, n. 4, pp. 2053-2059, 2016.

[7] A. Kawashima, K. Kobayashi, and K. Watanabe, "Implementation of Human-Like Driving for Autonomous Vehicle,” SAE Technical Paper 2001-01-0805, 2001. doi: 10.4271/2001-01-0805.

[8] ISO 15031-5:2011 (E), Road vehicles - Communication between vehicle and external equipment for emissionsrelated diagnostics. Part 5: Emissions-related diagnostic services. Second edition, 2011.

[9] S. Pala, "HUD Future in the Driverless Vehicle Society: Technology Leadership Brief," SAE Technical Paper 201201-9022, 2012. doi: 10.4271/2012-01-9022.

[10] A. Saykin, "A new concept of environmentally friendly transport," LAP LAMBERT Academic Publishing, Moscow, No. 978-3-659-39217-7, pp: 103, 2013.

[11] A. Ivanov, V. Prikhodko and S. Shadrin, "Development of the external indirect pressure control system in pneumatic tires,” Life Science Journal, T. 11, 12 (s), pp. 336, 2014.

[12] V. Prikhodko, A. Ivanov and S. Shadrin, "The development of additional services using vehicle to person (V2P) interface,” Life Science Journal, T. 12, 12 (s), pp. 862, 2014.

[13] R. Felix, J. Economou, K. Knowles, "Driverless Vehicles and LIDAR: Evaluation of Possible Security Threats on the Open Road,” SAE Technical Paper 2015-01-0219, 2015. doi: 10.4271/2015-01-0219.

[14] Hybrid and Electric Vehicles, IEA, Germany, pp: 328, 2015.

[15] S. Shadrin, A. Ivanov and K. Karpukhin, "Using data from multiplex networks on vehicles in road tests, in intelligent transportation systems, and in self-driving cars," Russian engineering research, vol. 36, n. 10, pp. 811814, 2016.

[16] H. Dakroub, A. Shaout and A. Awajan, “Connected Car Architecture and Virtualization,” SAE Int. J. Passeng. Cars - Electron. Electr. Syst., vol. 9, n. 1, pp. 153-159, 2016. doi: 10.4271/2016-01-0081.

[17] S. Shadrin A. Ivanov, "Algorithm of autonomous vehicle steering system control law estimation while the desired trajectory driving,” ARPN Journal of Engineering and Applied Sciences, vol. 15, n. 11, pp. 9312-9316, 2016. 